
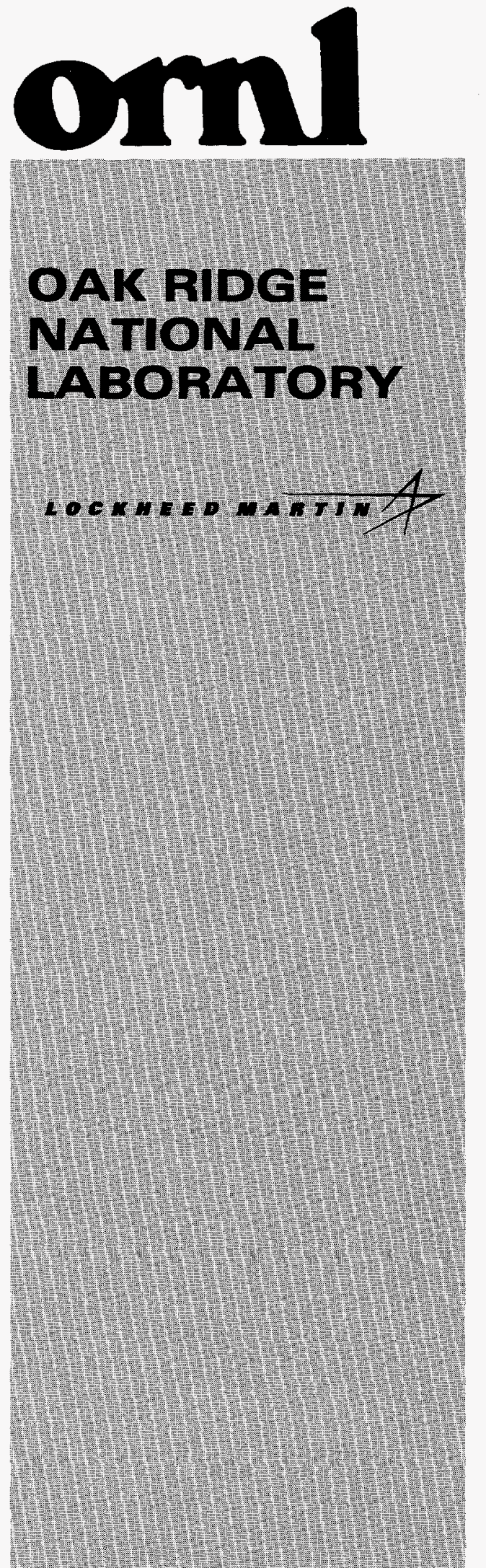

HAMAGED AND OPERATED BY

LOCKREEO MARMI ENERGY RESEARCH CORPORATION FORTHE UMTIED STATES

DEPARTIMENT OF ENERGY

ORNL/CON-452

\title{
Ancillary-Service Details: Operating Reserves
}

\author{
Eric Hirst \\ Brendan Kirby
}


This report has been reproduced directly from the best available copy.

Avaliable to DOE and DOE contractors from the Office of Scientific and Technical Information, P.O. Box 62, Oak Ridge, TN 37831; prices available from (423) 576-8401, FTS 626-8401.

Available to the public from the National Technical Information Service, U.S. Department of Commerce, 5285 Port Royal Rd., Springfield, VA 22161.

This report was prepared as an account of work sponsored by an agency of the United States Government. Neither the United States Government nor any agency thereof, nor any of their employees, makes any warranty, express or implied, or essumes any legal liability or responsibility for the accuracy, completeness, or usefulness of any information, apparatus, product, or process disclosed, or represents that its use would not infringe privately owned rights. Reference herein to any specific commercial product, process, or service by trade name, trademark, manufacturer, or otherwise, does not necessarily constitute or imply its endorsement, recommendation, or favoring by the United States Government or any agency thereof. The views and opinions of authors expressed herein do not necessarily state or reflect those of the United States Government or any agency thereof. 
ENERGY DIVISION

\title{
ANCILLARY-SERVICE DETAILS: OPERATING RESERVES
}

\author{
ERIC HIRST and BRENDAN KIRBY
}

November 1997

Sponsored by

The National Regulatory Research Institute Columbus, Ohio

and

Office of Utility Technologies

Office of Energy Efficiency and Renewable Energy

U.S. Department of Energy

OAK RIDGE NATIONAL LABORATORY

Oak Ridge, Tennessee 37831

managed by

LOCKHEED MARTIN ENERGY RESEARCH CORPORATION

for the

U.S. DEPARTMENT OF ENERGY

under contract No. DE-AC05-96OR22464

ImTHEUTION OP NM DOCUMENT IS UNLMITED 


\section{DISCLAIMER}

Portions of this document may be illegible electronic image products. Images are produced from the best available original document. 


\section{CONTENTS}

Page

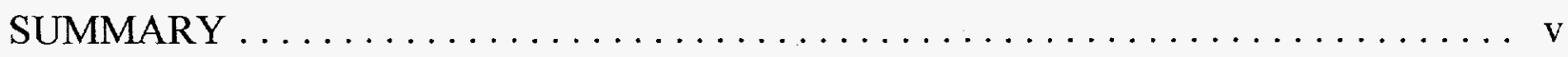

LIST OF ACRONYMS $\ldots \ldots \ldots \ldots \ldots \ldots \ldots \ldots \ldots \ldots \ldots \ldots \ldots \ldots \ldots \ldots \ldots \ldots \ldots$ vii

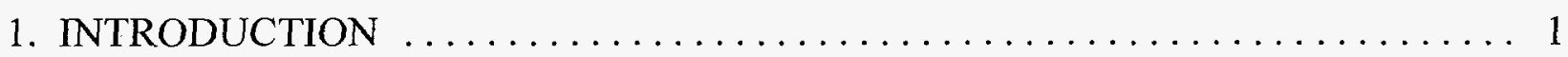

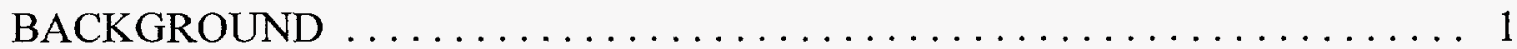

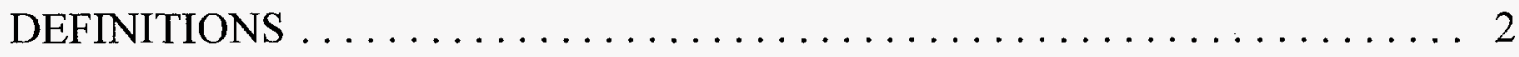

APPLICATION OF OPERATING RESERVES $\ldots \ldots \ldots \ldots \ldots \ldots \ldots \ldots, 3$

2. NERC AND REGIONAL DEFINITIONS AND REQUIREMENTS $\ldots \ldots \ldots \ldots \ldots$

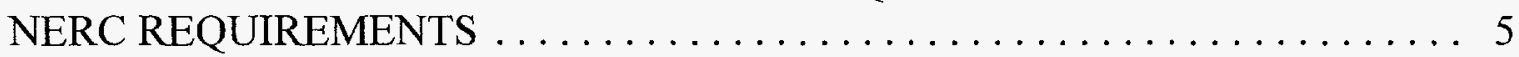

REGIONAL-RELIABILITY-COUNCIL REQUIREMENTS $\ldots \ldots \ldots \ldots \ldots \ldots 7$

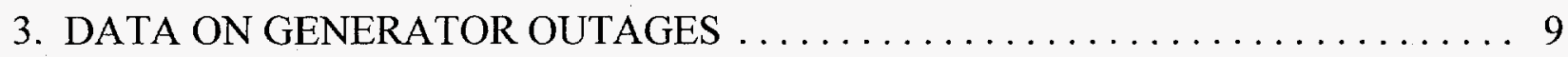

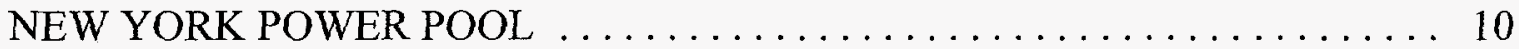

ELECTRIC RELIABILITY COUNCIL OF TEXAS $\ldots \ldots \ldots \ldots \ldots \ldots \ldots, 12$

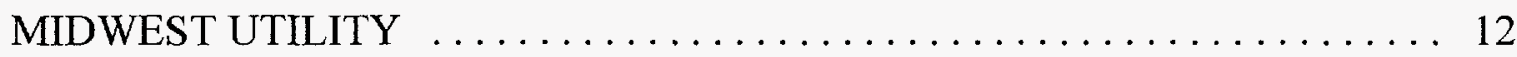

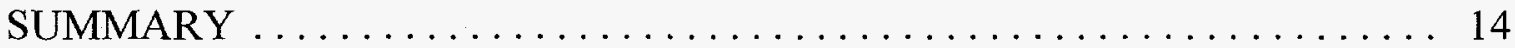

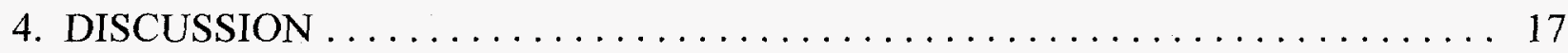

TECHNICAL BASIS FOR OPERATING-RESERVE REQUIREMENTS . . . . . 17

PAYING FOR OPERATING RESERVES $\ldots \ldots \ldots \ldots \ldots \ldots \ldots \ldots \ldots \ldots$

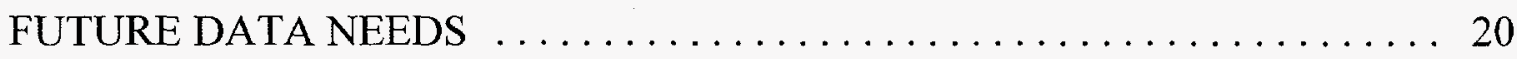

MIXING FUNCTIONS WITHIN OPERATING RESERVES $\ldots \ldots \ldots \ldots \ldots 20$

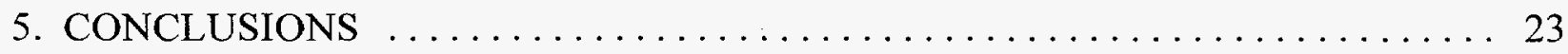

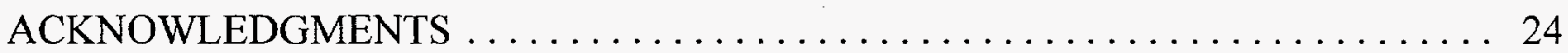

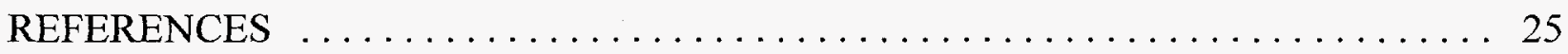





\section{SUMMARY}

Operating reserves are the front lines in the defense of bulk-power systems against major generation and transmission outages. Operating reserves are provided by generating units that can increase their output rapidly to restore the system to generation/load balance after a major disturbance occurs.

Dramatic changes are under way in the U.S. electricity sector, in particular the unbundling of generation from transmission and the increasingly competitive nature of bulkpower markets. Therefore, it is important to revisit the industry's definitions of, procurement of, and payment for operating reserves. The procedures traditionally used by vertically integrated utilities may not serve the needs of an increasingly fragmented and competitive electricity industry.

This report examines the past and current functions of, as well as the national and regional requirements for, operating reserves. We examine the data and analysis that support minimum-operating-reserve requirements. We obtained data on the number and severity of generator outages for three large U.S. electrical systems, including a power pool, a regional reliability council, and a utility. These limited data sets show a range of 15 to 40 major $>500$ $\mathrm{MW}$ ) outages a year for systems ranging in size from $20,000 \mathrm{MW}$ to $48,000 \mathrm{MW}$ of peak demand (Fig. S-1).

Finally, we discuss several emerging issues related to the underlying technical support for minimum operating-reserve requirements, alternative ways to pay for these reserves, the data needed to support the analysis of these requirements, and the mix of functions that are currently included within operating reserves. Our recommendations include the following:

- The North American Electric Reliability Council and the regional reliability councils should collect, analyze, and publish additional data on the frequency and severity of outages and the factors that determine the time required to restore electrical systems to balance. These factors may include the amount of operating reserves available at that time, their ramp rates, and system load. These analyses should be conducted with both the traditional deterministic approaches as well as probabilistic methods. The results of such analyses should provide a stronger and more defensible basis for the regional requirements for minimum operating reserves.

- To the extent possible, competitive markets should be used to acquire and pay for reserves. Such a system could assign operating-reserve responsibility and costs to individual generators on the basis of their reliability (e.g., frequency of outages), size, and other important factors. Such a system would provide the correct incentives to the 


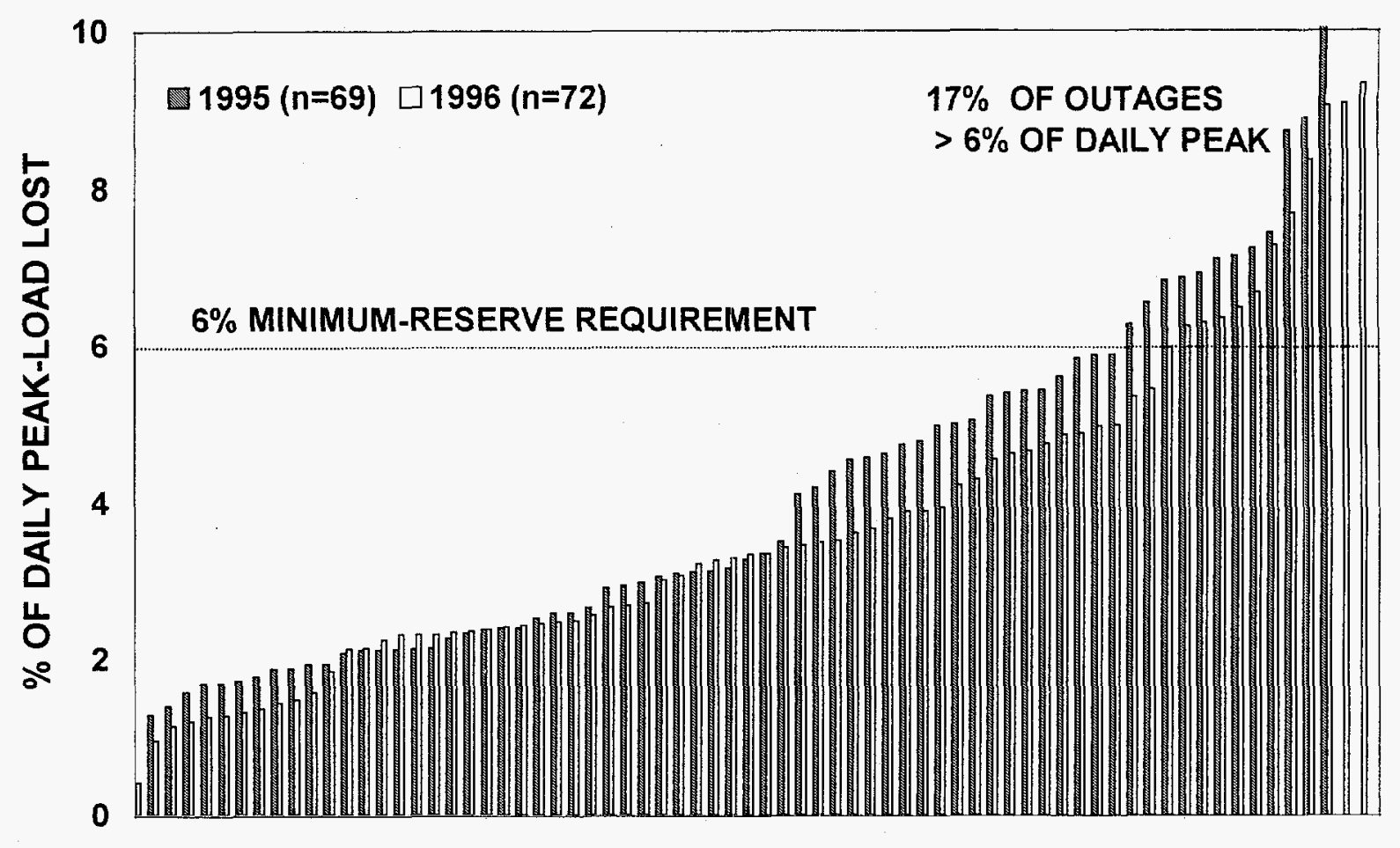

Ecarfor

\section{INDIVIDUAL OUTAGES}

Figure S-1. Distribution of generator outages for 1995 and 1996 for a large Midwestern utility as a function of outage size relative to daily peak load. Outages occur during fewer than $1 \%$ of the hours, and $17 \%$ of the outages exceed the region's minimum-operating-reserve requirement.

owners of generating units, encouraging them to balance the costs of operations and maintenance against the costs of paying for operating reserves.

- Operating reserves are currently used to meet several functions related to both system reliability and commercial transactions. In particular, reserves are used to protect bulkpower systems against the loss of major generation and transmission resources (the reliability function). They are also often used to correct for load-forecast errors, a purely commercial function. This latter function should be assigned to a separate ancillary service, either load following or energy imbalance, and not commingled with operating reserves.

Because of electricity's unique characteristics, both in powering the U.S. economy and in its technical features, the role of operating reserves in "keeping the lights on" is absolutely critical. The changes outlined above and discussed in this report should help to ensure that reliability is maintained as we transform the U.S. electricity industry from one dominated by heavily regulated, vertically integrated utilities to one dominated by competitive forces acting on a much larger number of diverse participants. 


\section{LIST OF ACRONYMS}

ACE Area-control error

AGC Automatic-generation control

ECAR East Central Area Reliability Coordination Agreement

ERCOT Electric Reliability Council of Texas

FERC U.S. Federal Energy Regulatory Commission

NERC North American Electric Reliability Council

NYPP New York Power Pool 


\section{INTRODUCTION}

\section{BACKGROUND}

Electricity is the ultimate "real-time" product, with its production, transportation, and consumption occurring within a fraction of a second. Because electricity moves at the speed of light and cannot readily be stored, bulk-power systems must maintain a continuous and nearinstantaneous balance between generation and load.

For three reasons, utilities traditionally have gone to great lengths to design, build, and operate these systems with considerable backup capabilities. First, generation and transmission equipment occasionally fail. Second, because transmission systems are highly interactive, failure to maintain a continuous generation/load balance could lead to cascading failures and collapse of the electrical system. Third, electricity is a vital element in modern society.

The Federal Energy Regulatory Commission's decision (FERC 1996 and 1997) to require utilities to functionally unbundle generation from transmission exposed to view an array of bulk-power functions called ancillary services (Hirst and Kirby 1996). These services are required to maintain system reliability and to effect commercial transactions. A careful examination of operating reserves is needed now because of both the unbundling of generation and transmission and the growing competition within the generation sector of the electricity industry.

Electric utilities have traditionally provided operating reserves as part of the bundled product they sold to their customers. Utilities and their state regulators implicitly agreed on the level of reliability to be maintained (and, therefore, on the amount of reserves that each utility carried). In the increasingly competitive electricity industry, transmission-system operators will be commercially independent of generator operation and output sales. Because reliability rules can have substantial effects on the profits from energy production and sales, many entities will closely scrutinize these rules for their effects on their earnings.

This report focuses on an essential component of this backup capability, operating reserves. We define these reserves and show how they are used to quickly restore the electric system to equilibrium after a major outage. Chapter 2 describes the rules that the North American Electric Reliability Council (NERC) and its regional reliability councils use to specify the minimum levels of operating reserves that each electrical system must maintain. Chapter 3 presents and analyzes the empirical — data and analytical-basis for these reserve requirements. We present data on generator outages and system responses for a power pool (New York), a large Midwestern utility, and a reliability region (the Electric Reliability Council 
of Texas, ERCOT). Chapter 4 discusses several issues related to the technical basis for operating-reserve requirements, payment for operating reserves, future data needs, and disaggregation of the several purposes that operating reserves currently serve. Chapter 5 summarizes our findings and conclusions from this study.

\section{DEFINITIONS}

Operating reserves are provided by generating units that can respond to the sudden and unexpected loss of a supply resource (such as a major generating unit or a large transmission line) quickly enough to maintain system stability and restore the system to generation/load balance and to the reference interconnection frequency. Operating reserves are divided into two components (Hirst and Kirby 1996):

- Spinning reserve, the use of generating equipment that is online and synchronized to the grid that can begin to increase output immediately in response to changes in interconnection frequency and that can be fully available within 10 minutes to correct for generation/load imbalances caused by generation or transmission outages. Almost all generators that supply spinning reserve are equipped with governors and automaticgeneration control (AGC). In principle, loads that are frequency responsive or that are under the control of the system operator could help provide this service. (Under the current system, frequency-responsive loads, such as motors, automatically provide reserves but without compensation.) This service can be provided by any generator that is connected to the grid and electrically close enough to the local control area that transmission limitations do not prevent the importation of its power.

- Supplemental reserve, the use of generating equipment and interruptible load that can be fully available within 10 minutes to correct for generation/load imbalances caused by generation or transmission outages. Supplemental reserve differs from spinning reserve in that supplemental reserve need not be synchronized to the grid and need not begin responding to an outage immediately. Indeed, bringing a combustion turbine from a cold condition to full output requires several minutes.

The 10-minute requirement for complete response is set by NERC and is therefore consistent throughout North America. However, the amount of time that these reserves must remain in service after full response is obtained differs among regions and is sometimes undefined. For example, the California Independent System Operator proposal (Pacific Gas and Electric et al. 1997) requires that operating reserves must be capable of being maintained for two hours. Idaho Power's ancillary-services tariff specifies that operating reserves will be made available until the end of the clock hour after the contingency occurred (i.e., for a minimum of 60 minutes and a maximum of 120 minutes). The Mid-America Interconnected Network (1995)

"In competitive markets characterized by active spot prices for energy and ancillary services, customer interruptions of some or all of their loads could contribute substantially to operating reserves. 
requires its members "to restore their operating reserve to the stated minimum levels as soon as practicable" but does not provide specifics on what "practicable" means.

Some systems, including the New England Power Pool (1996) and the California proposal, add a third element to operating reserves, sometimes called replacement reserve. This service is the provision of generating capacity that must be fully available within 30 or 60 minutes (the exact time depends on the rules of the regional reliability council) and can then be maintained until commercial arrangements can be made by the supplier or customer (e.g., for two hours) to "back up" the normal supply for the load (Interconnected Operations Services Working Group 1997). Thus, replacement reserve serves as a backup for operating reserves to protect against a second contingency.

The FERC (1996 and 1997) definition of supplemental reserve is ambiguous. It could mean (1) the reserve required to respond to a contingency (as defined above) or (2) slower reserves that are used to back up operating reserves and protect against a second contingency (e.g., California's replacement reserve).

\section{APPLICATION OF OPERATING RESERVES}

Figure 1 illustrates how the electric system is intended to operate when a major generating unit suddenly trips offline (Virmani, Lo, and McNair 1992). Prior to the outage, system frequency is very close to its $60-\mathrm{Hz}$ reference value. Generally, within a second after the outage occurs, frequency drops, in this case to just over $59.9 \mathrm{~Hz}$. The frequency decline is arrested primarily because many electrical loads (e.g., motors) are frequency responsive; that is, their demand varies with system frequency. (If the contingency is sufficiently large, underfrequency relays will automatically interrupt certain loads.) Once the frequency decline exceeds the deadband of the generator governors, the governors at those generators so equipped sense the frequency decline and open valves on the steam turbines, which rapidly increases generator output. After a few more seconds, generator output declines slightly because the higher steam flow through the turbine is not matched by the steam flow from the boiler to the turbine. At this point, the operating reserves, in response to AGC signals from the control center, kick in. More fuel is added to the boiler, leading to a faster rate of steam production, which leads to higher power output. In the Figure-1 example, the system worked as it was intended to, and frequency (as well as area-control error, ACE) was restored to its precontingency $60-\mathrm{Hz}$ reference value within the required ten minutes.

How many major outages occur that cause frequency to drop as discussed above (Fig. 1)? Incomplete data from NERC suggest that outages of $1000 \mathrm{MW}$ or more occur only a couple of times per month in the Eastern Interconnection (Wright 1997); see Fig. 2. The data also suggest that outages occur more frequently in the winter and summer peaking months (February, July, and August). 


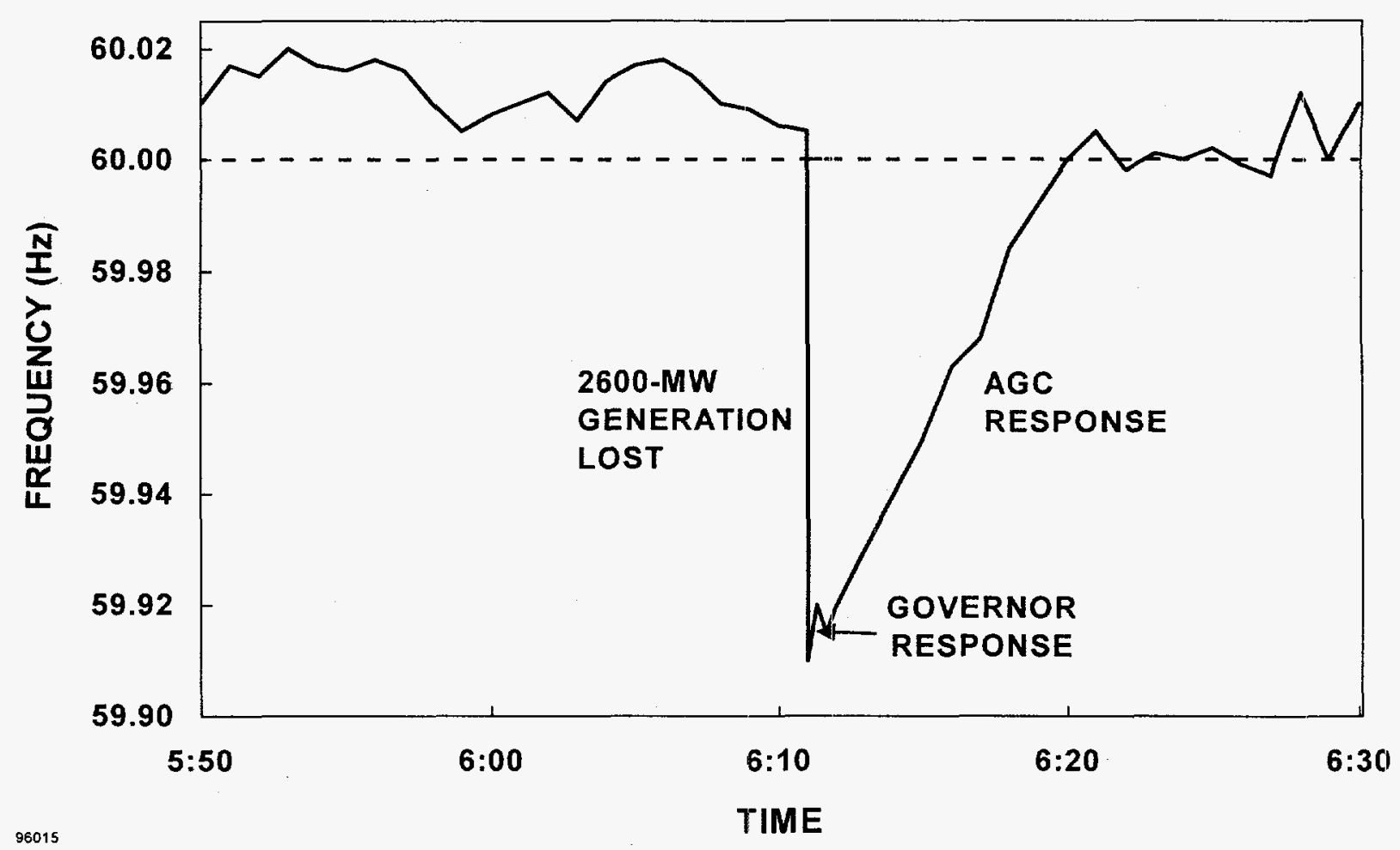

Figure 1. Interconnection frequency before and after the loss of a 2600-MW generating unit.

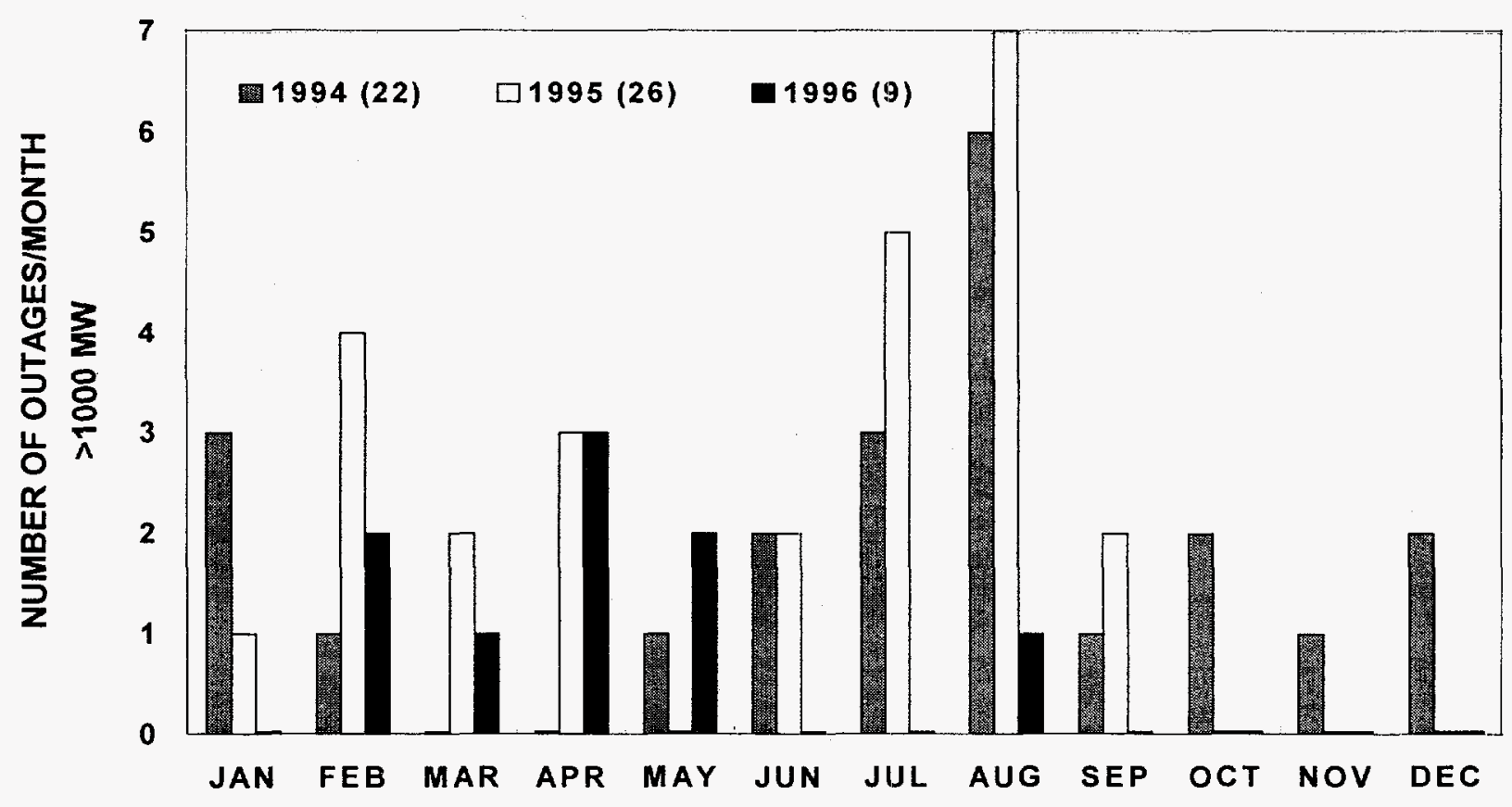

Figure 2. Incomplete data on the number of large-generator outages in the Eastern Interconnection in 1994, 1995, and 1996. 


\section{NERC AND REGIONAL DEFINITIONS AND REQUIREMENTS}

To understand the purpose and use of operating reserves, one must first understand the concept of a control area and its functions. NERC (1995) defines a control area as: "An electrical system bounded by interconnection (tie line) metering and telemetry. It controls its generation directly to maintain its interchange schedule with other control areas and contributes to frequency regulation of the Interconnection." There are four bulk-electric systems (interconnections) in North America: Eastern, Western, ERCOT, and Quebec. Within each interconnection, all the generators are synchronized and therefore operate at the same frequency, and electricity flows freely on AC transmission lines. Electricity flows between the four interconnections is limited and occurs only on DC links.

Control areas seek to minimize any adverse effect they might have on other control areas within the interconnection by minimizing their ACE. The ACE equation, in slightly simplified form, is:

$$
\mathrm{ACE}=\left(\mathrm{I}_{\mathrm{A}}-\mathrm{I}_{\mathrm{S}}\right)-10 \beta\left(\mathrm{F}_{\mathrm{A}}-\mathrm{F}_{\mathrm{S}}\right)
$$

where I refers to the algebraic sum of all real power (MW) flows on the tielines between an individual control area and its surrounding control areas, $\mathrm{F}$ is the interconnection frequency $(\mathrm{Hz}), \mathrm{A}$ is actual, $\mathrm{S}$ is scheduled, and $\beta$ is the control area's frequency bias $(\mathrm{MW} / 0.1 \mathrm{~Hz})$. The first term shows how well the control area performs in matching its schedules with other control areas (i.e., how well it matches its generation plus net incoming scheduled flows to its loads). The second term is the individual control area's contribution to the interconnection to maintain frequency at its scheduled value (usually $60 \mathrm{~Hz}$ ). Thus, ACE is the instantaneous difference between actual and scheduled interchange, taking into account the effects of frequency.

\section{NERC REQUIREMENTS}

NERC's (1995) criteria for operating reserves specifies:

Each control area shall operate its MW power resources to provide for a level of operating reserve sufficient to account for such factors as errors in forecasting, generation and transmission equipment unavailability, number and size of generating units, system equipment forced outage rates, maintenance schedules, power flows.

*Phase-angle regulators and DC lines within each interconnection provide limited capacity to control 
regulating requirements, and regional and system load diversity." Following loss of resources or load, a control area shall take appropriate steps to reduce its Area Control Error to zero within 10 minutes. It shall take prompt steps to protect itself against the next contingency.

Until recently, NERC's (1995) standards for "disturbance conditions" consisted of two elements:

B1 Standard. The ACE must return to zero within ten minutes following the start of the disturbance.

B2 Standard. The ACE must start to return to zero within one minute following the start of the disturbance.

The 10-minute full-response requirement associated with operating reserves derives from the B1 standard, while the need for spinning reserve derives from the B2 standard.

NERC's (1996) new Disturbance Control Standard, which will go into effect in January 1998 , replaces the B1 and B2 standards with a single quantitative measure of control-area performance:

During a disturbance, controls cannot usually maintain ACE within the criteria for normal load variation. However, an area is expected to activate operating reserve to recover $\mathrm{ACE}$ within ten minutes. For purposes of disturbance control compliance, a reportable disturbance is defined as an event whose magnitude is less than or equal to the magnitude of an affected control area's most severe contingency, or is greater than or equal to $80 \%$ of the magnitude of the control area's most severe single contingency loss.

A Control Area shall return its ACE either to zero or to its pre-disturbance ACE level within ten minutes following a disturbance.

A control area ... must calculate and report compliance with the Disturbance Control Standard ... . Each control area ... shall meet the Disturbance Control Standard $100 \%$ of the time for reportable disturbances. Disturbance Control Standard is measured as the percentage recovery, $R_{i}$.

This recovery factor is defined as:

$$
\mathrm{R}_{\mathrm{i}}=100 \% \times\left[\mathrm{MW}_{\mathrm{LOSS}}-\operatorname{Max}\left(0, \mathrm{ACE}_{\mathrm{A}}-\mathrm{ACE}_{\mathrm{M}}\right)\right] / \mathrm{MW}_{\mathrm{Loss}},
$$

'NERC's definition of operating reserves is much more expansive than ours. We discuss these differences in Chapter 4. 
where:

$\mathrm{MW}_{\text {Loss }} \quad$ is the MW size of the disturbance as measured at the beginning of the loss,

$\mathrm{ACE}_{\mathrm{A}} \quad$ is the pre-disturbance $\mathrm{ACE}$ if $\mathrm{ACE}_{\mathrm{A}}<0$ and 0 if $\mathrm{ACE}_{\mathrm{A}} \geq 0$,

$\mathrm{ACE}_{\mathrm{M}} \quad$ is the maximum algebraic value of $\mathrm{ACE}$ measured within the ten minutes following the disturbance event.

\section{REGIONAL-RELIABILITY-COUNCIL REQUIREMENTS}

The minimum operating-reserve requirements differ from region to region (Interconnected Operations Services Working Group 1997*). In the East Central Area Reliability Coordination Agreement (ECAR), the requirement is set equal to $6 \%$ of the projected daily peak demand. In ERCOT (1997), the responsive-reserve requirement is a set amount, $2300 \mathrm{MW} .^{\#}$ In the other regions, the requirement is based on either the largest generating unit online or the single most severe contingency (either a large generator or critical transmission line).

The requirement for minimum levels of operating reserves could be based on either probabilistic or deterministic calculations. In most regions, the requirement is deterministically calculated based on the $\mathrm{N}-1$ criterion. Thus, these requirements are independent of the reliability performance of the generating units in the particular region. The Western Systems Coordinating Council (1997) is the only region with an operating-reserve requirement that recognizes differences among generators in their reliability. It requires reserves equal to $5 \%$ of the load supplied by hydroelectric resources plus $7 \%$ of the load supplied by thermal generation. [This difference in reserve requirements may also reflect the higher ramp rates (in $\mathrm{MW} /$ minute) of hydro units.] However, no region incorporates the reliability of individual units in its determination of the minimum operating-reserve requirement.

Historically, it may not have been important to recognize the frequency of forced outages at individual generators because utilities provided operating reserves from their own portfolio of generating resources and sold this service as part of the bundled electricity product. In the future, with generation unbundled from transmission and with generation increasingly competitive, system operators may need to recognize differences in reliability among generators. These differences could affect both the amount of reserves required and the allocation of costs among generators. Figure 3 shows the number of forced outages for coal-

"See Appendix $\mathrm{C}$ of that report for additional details on these requirements and how they are split between spinning and supplemental reserves.

${ }^{\#}$ ERCOT's definition of responsive reserve is more limited than the operating reserves as defined by other regions. In particular, ERCOT's responsive reserve is used only to protect against forced outages, not to adjust for load-forecast errors, regulation requirements, or other factors. 


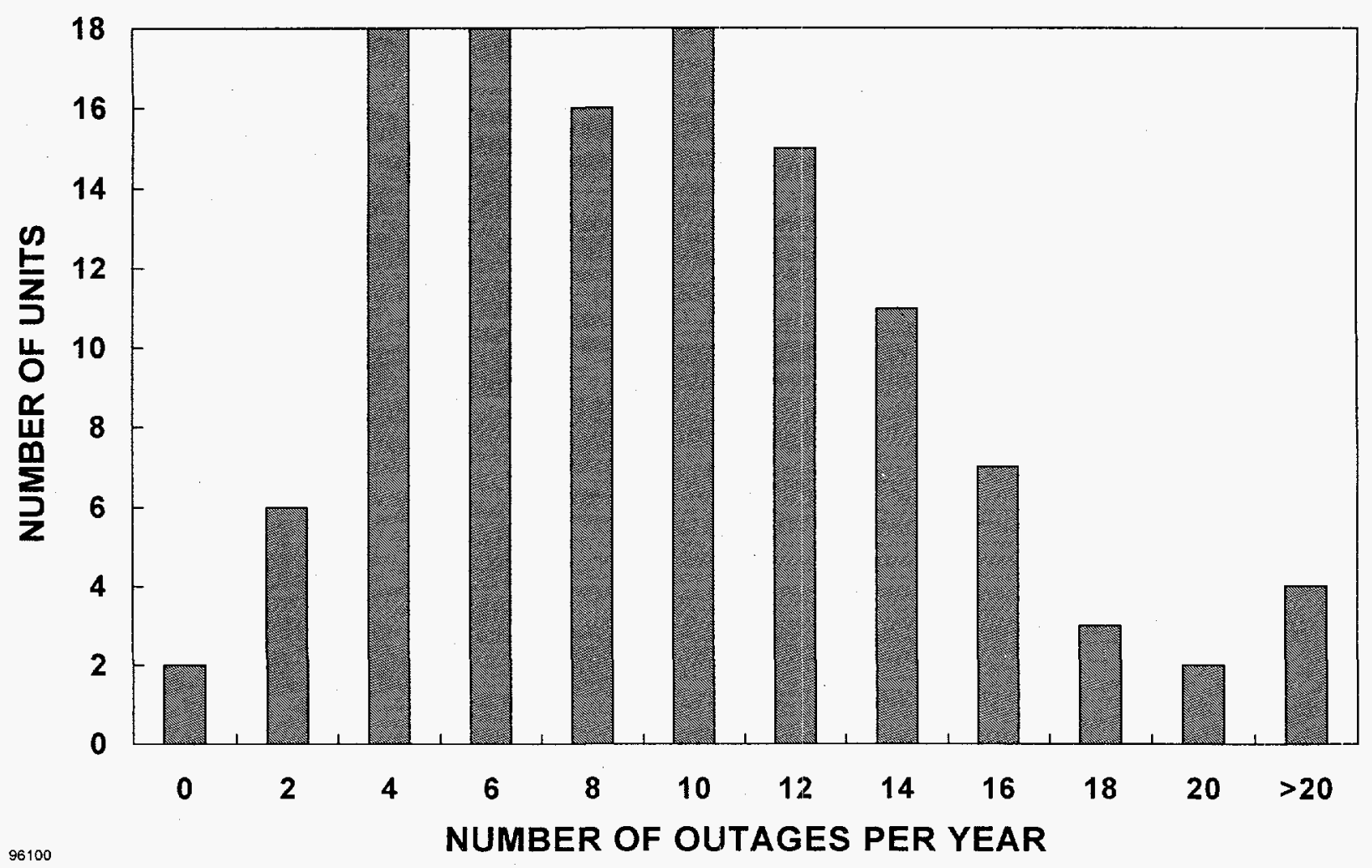

Figure 3. Number of forced outages in 1996 for 120 coal-fired generating units between 600 and $800 \mathrm{MW}$ in size.

fired units between 600 and $800 \mathrm{MW}$ for 1996 (Curley 1997). Although, on average, these 120 units experienced nine outages a year, two units had none while, at the other extreme, five units had 20 or more outages.

In many cases, the regional requirements for operating reserves include services beyond those associated with protection against generator and transmission outages. Specifically, these reserves are typically used to account for load forecasting error and sometimes include the generation assigned to regulation. For example, ERCOT (1997) defines operating reserve as "that capability above system demand required to provide for regulation, load forecasting error, and equipment forced outages."

Finally, we uncovered only limited technical support for the minimum operating-reserve requirements set by the various regions. We reviewed a 10-year old study from ERCOT (1987) that demonstrated the adequacy of its spinning-reserve requirement. The study analyzed the stability, voltages, power flows, and frequency at various locations in Texas for the first 15 seconds after an outage occurs. The PJM Interconnection sent us several studies, the most recent of which was completed 21 years ago (Cucchi, Pratzon, and Witmer 1976). We know that system operators frequently conduct such contingency studies, but apparently these studies are rarely published. These studies appear to be aimed more at assuring that the existing reserve requirements are adequate and less at establishing the minimum requirements. 


\section{DATA ON GENERATOR OUTAGES}

We contacted several utilities, power pools, and regional reliability councils to obtain data on outages and the time to recovery from those outages. We had planned to conduct an exploratory analysis of generator outages and the determinants of the recovery time from such outages. We had hoped that such an effort would assist NERC and the regional reliability councils in deciding whether and how to develop stronger analytical bases for today's rules on the minimum amounts of reserves that each control area must maintain, as well as in developing, implementing, and enforcing NERC's new disturbance control standard.

Specifically, we requested data for each control area on the following variables at the time of each outage:

- the number of generating units online

- the number of units providing spinning and supplemental reserves

- the amount of generating capacity committed to operating reserves

- the amount of generation lost because of the outage

- the amount of operating reserves lost because of the outage

- the current hourly and daily peak loads

- the current spot price of electricity (or system lambda)

- the time to restore $\mathrm{ACE}$ and frequency to their pre-disturbance values

Ultimately, we obtained data for only three control areas. Our discussions with system operators and planners at several utilities, reliability councils, and power pools uncovered several reasons why such data often could not be provided. In many cases, these people were extremely busy with other, more pressing projects. As examples, they were developing or responding to new NERC and regional reliability council requirements for system operation and control, , they were developing or responding to proposals to create independent system operators, or they were implementing electronic-information systems in response to FERC's requirements. As one respondent wrote, "we do not presently have sufficient staff resources to devote toward supplying the data you are requesting as much of it is in a form that would require significant effort to compile."

*In January 1997, the NERC Board decided to convert the current bulk-power reliability system from one of voluntary compliance with NERC standards to one of mandatory compliance. 
In other cases, we were told that the data were considered proprietary and not for public release. In every case, we were told that many of the data elements we requested were simply not available (although most of the people we talked with agreed that the list shown above is a reasonable one). In several cases, even the most basic data (e.g., the magnitude of the outage and the time to restore ACE to its pre-disturbance value) were not made available. As one utility staffer put it "We have two problems here at ..., the accuracy of the data and our inability to store it for long periods of time. We are working on these issues."

Table 1 summarizes the results we obtained from NYPP, ERCOT, and a large utility in ECAR. Normalized by system peak load, the ECAR utility has more than four times as many large (greater than $500 \mathrm{MW}$ ) outages as does ERCOT and about twice as many outages as does NYPP.

Table 1. Size and number of generator outages from three systems

\begin{tabular}{|c|c|c|c|c|}
\hline & \multirow[t]{2}{*}{ NYPP } & ERCOT $^{\mathrm{a}}$ & \multicolumn{2}{|c|}{ ECAR utility } \\
\hline & & $-->500 \mathrm{MW}$ & 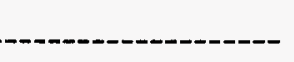 & All \\
\hline Peak load (MW) & 27,000 & 48,000 & \multicolumn{2}{|c|}{ - 20,000 - - } \\
\hline 1995 & 20 & not available & 38 & 69 \\
\hline 1996 & 15 & 21 & 39 & 72 \\
\hline
\end{tabular}
$500 \mathrm{MW}$.

${ }^{2}$ During the first half of 1997, ERCOT experienced 10 generator outages greater than

NEW YORK POWER POOL

The New York Power Pool (NYPP) has a peak demand of about 27,000 MW and a load factor of 62\%. NYPP provided copies of its NPCC Interconnected Systems Trouble and Reserve Response Report for each major outage in 1995 and 1996. Each 1-page report presents the date and time of the outage; its magnitude; the amount of load lost (if any); the times to return ACE to its initial (pre-contingency value) and to zero; the extent to which reserves were sought and obtained from neighboring systems; and the values of scheduled interchange, actual interchange, and $\mathrm{ACE}$ from the time of the disturbance until 15 minutes later. We obtained hourly system load for each outage from FERC Form-1.

The NYPP experienced 20 large outages in 1995 and 15 such outages in 1996. The outages varied in size from 500 to $1000 \mathrm{MW}$, with averages of $640 \mathrm{MW}$ in 1995 and $750 \mathrm{MW}$ in 1996. Relative to the hourly system load, the 1995 outages ranged in size from 2 to nearly $7 \%$, with an average of $3.6 \%$.

Figure 4 shows the time for $\mathrm{ACE}$ to return to its pre-contingency value. The average time for ACE recovery in both 1995 and 1996 was under eight minutes, with only one 
occurrence for which the recovery time exceeded NERC's 10-minute requirement. In 1995, none of the outages exceeded $80 \%$ of the most severe single contingency (about $1130 \mathrm{MW}$ ). In 1996, six of the outages were large enough to trigger the Disturbance Control Standard calculation. In each case, the recovery occurred within the 10-minute limit. Thus, NYPP had a perfect record in terms of the new Disturbance Control Standard for both 1995 and 1996.

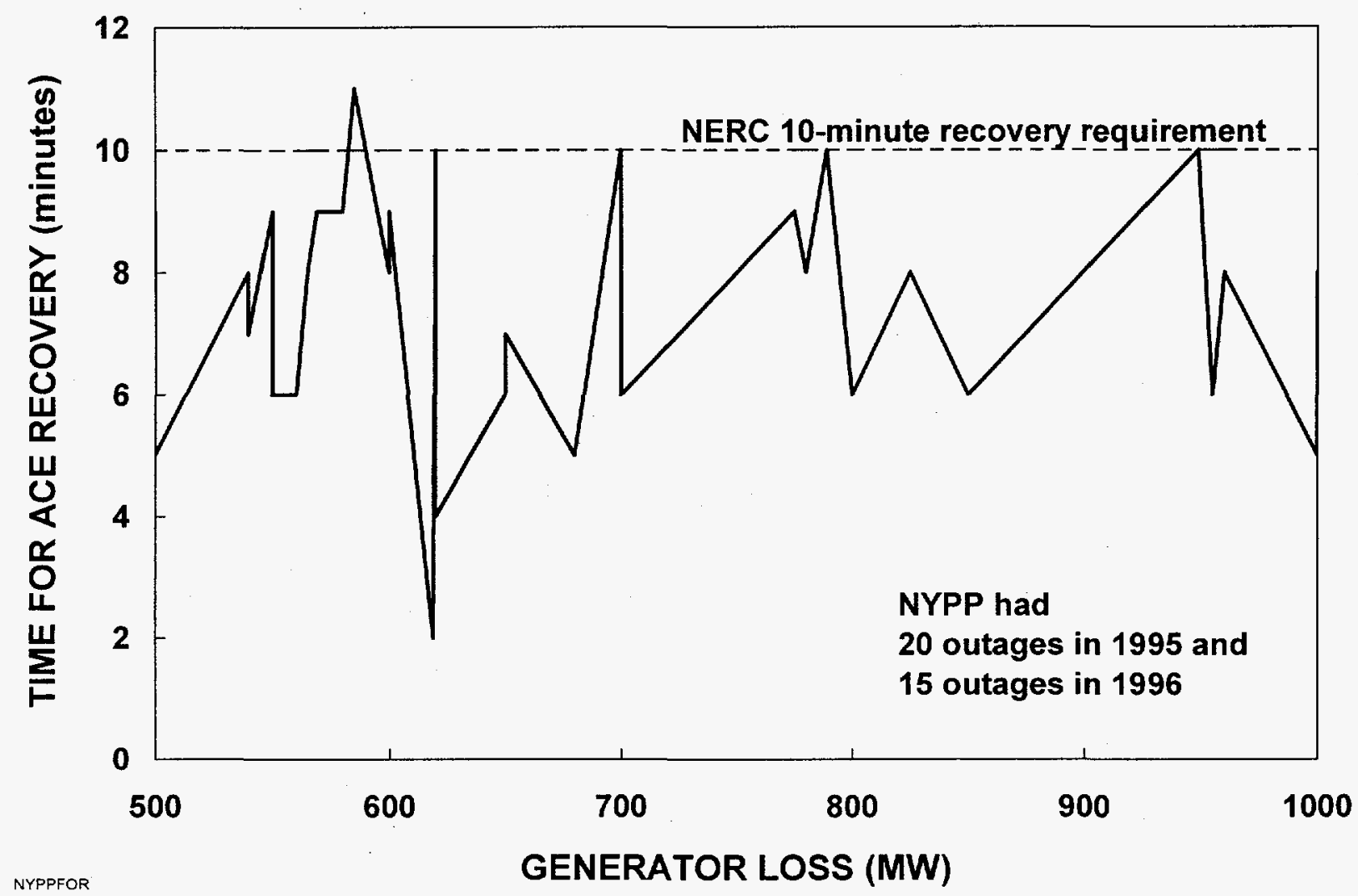

Figure 4. The time required for $\mathrm{ACE}$ to return to the lesser of its pre-contingency value or zero after loss of a major generating unit $(>500 \mathrm{MW})$ as a function of the size of the outage for the New York Power Pool.

The results in Figure 4 show essentially no correlation between the magnitude of the generation outage and the amount of time required to bring the system back into balance. We found this result surprising, because our intuition suggested that the recovery time would vary with the size of the outage. (Recovery time could also be a function of the severity of the drop in frequency and the amount of generation currently online and the ramp rates of these units. For example, recovery times may be longer during the typical morning rampup when system loads increase substantially. At such times, generators assigned to load following are ramping at or near their maximum rates and, in a sense, are competing with operating reserves.)

"The largest contingency in New York is either the Nine Mile Point 2 unit (1055 MW), the transmission line to the two Bowline units $(1120 \mathrm{MW})$, or the high-voltage DC line to Quebec (1200 MW). 


\section{ELECTRIC RELIABILITY COUNCIL OF TEXAS}

ERCOT, encompassing most of Texas, is both a regional reliability council and an interconnection. Its peak demand is about $48,000 \mathrm{MW}$, and its load factor is $58 \%$. The ERCOT Disturbance Analysis reports we received covered 21 major outages in 1996 plus 10 such outages during the first half of 1997. Each one-page report provides data on the date and time of the outage, its magnitude, the amounts of load interrupted and automatically reduced, frequency just before and after the outage, and the time for frequency to return to its scheduled value. ERCOT, perhaps because of the small size of the interconnection, focuses on frequency rather than $\mathrm{ACE}$ in measuring response to outages. (For the interconnection as a whole, ACE is, by definition, always zero.)

ERCOT experienced 21 outages in 1996, ranging in size from 560 to $1185 \mathrm{MW}$, with an average of $830 \mathrm{MW}$. The time for frequency to return to its $60-\mathrm{Hz}$ reference value ranged from 4 to 25 minutes with an average of 11 minutes. Relative to the hourly ERCOT load, the outages ranged in size from 2 to $6 \%$ with an average of $3.2 \%$. Relative to the operating-reserve requirement of $2300 \mathrm{MW}$, the outages ranged from 24 to $51 \%$ with an average of $36 \%$.

During the first half of 1997, ERCOT experienced 13 generator outages, of which 10 were $500 \mathrm{MW}$ or more. For those 10 outages, the loss ranged from 540 to $1310 \mathrm{MW}$ with an average of $860 \mathrm{MW}$. The average time for recovery was 9 minutes, less than the 11 minutes for all 13 outages.

Figure 5 shows the time for frequency to return to its reference value for the 21 outages in 1996 and the 10 outages in the first half of 1997. As was true in New York, there is virtually no correlation between the size of an outage and the amount of time required to restore the system to balance.

\section{MIDWEST UTILITY}

This large Midwestern utility has a peak demand of 20,000 MW and a load factor of $66 \%$. It provided copies of its ECAR Disturbance Reports, which show for each outage the date and time, MW capability and MW lost from the unit, and the number of minutes for ACE to return to zero. (This utility provided information on all its generator outages in 1995 and 1996, not just those greater than $500 \mathrm{MW}$.)

This utility experienced 69 outages in 1995 and 72 in 1996, of which 38 and 39, respectively, were greater than $500 \mathrm{MW}$. Thus, roughly half the generator outages that this utility experienced were less than $500 \mathrm{MW}$. 


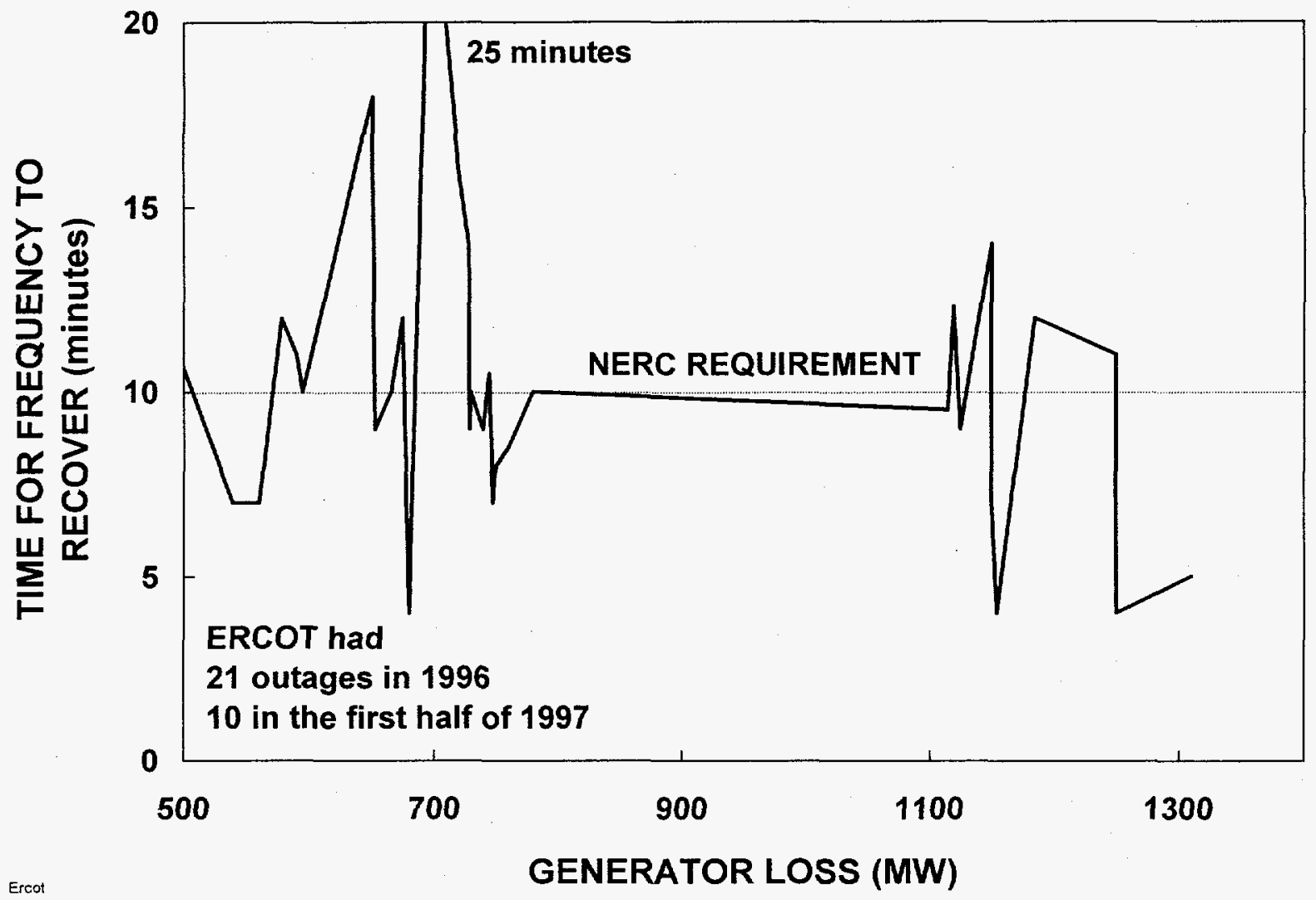

Figure 5. The time required to return frequency to its reference value after loss of a major generating unit (>500 $\mathrm{MW}$ ) as a function of the size of the outage for the Electric Reliability Council of Texas.

For the larger outages, the average time for ACE recovery was much higher for this utility than for either NYPP or ERCOT, 15 minutes in 1995 and 16 minutes in 1996 (Fig. 6). (Averaged over all outages, the recovery times were shorter, 12 minutes for 1995 and 13 minutes for 1996.) Relative to hourly load, these outages ranged in size from 3 to $10 \%$ and averaged about $6 \%$ for both years. Thus, compared with the NYPP and ERCOT outages, this utility experienced both larger and more frequent outages.

Because this utility experienced more outages than did the other two systems studied here, we examined these outage data for temporal correlations. We analyzed the data to see whether outages were more likely to occur at certain times of the day, on certain days of the week, or during certain months. The outages were least likely to occur at night (i.e., between $10 \mathrm{pm}$ and $6 \mathrm{am}$ ). The outage rates were about $50 \%$ higher on weekdays than on weekends 


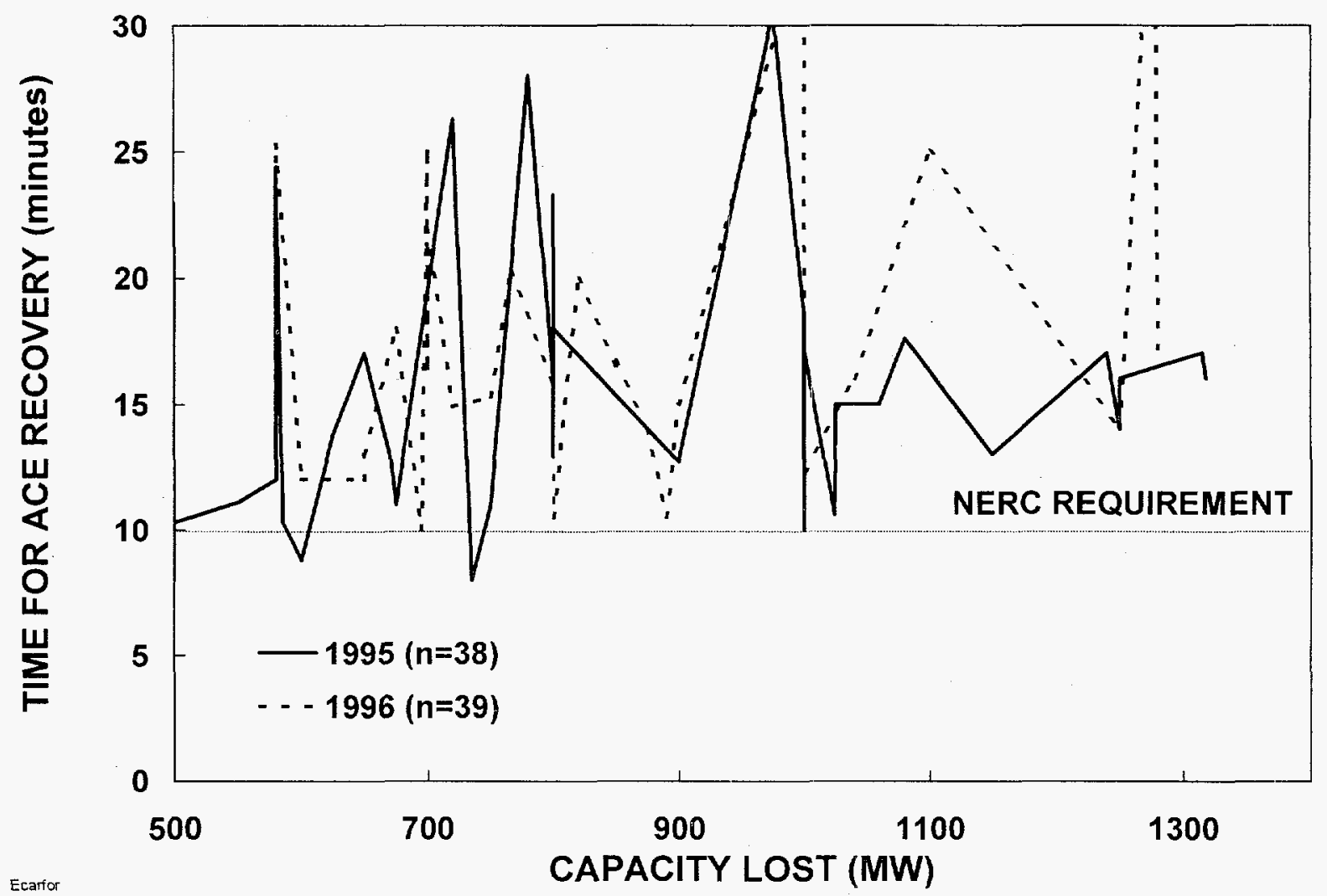

Figure 6. The time required to return ACE to zero after loss of a major generating unit ( $>500 \mathrm{MW}$ ) as a function of the size of the outage for an ECAR utility.

(Fig. 7).* And the outages showed little pattern from month to month, unlike the Eastern Interconnection data shown earlier (Fig. 2).

\section{SUMMARY}

These results, from three different systems, show substantial differences in the number of, extent of, and recovery from generator outages (Fig. 8). Relative to the minimum operatingreserve requirement, the outages in ERCOT and New York are much smaller than those for the ECAR utility. Specifically, the ERCOT outages range from 23 to $57 \%$ of the operating-reserve requirement, the NYPP outages range from 44 to $89 \%$, while the ECAR utility outages range from 51 to $169 \%$. Although the form of operating-reserve requirement differs among these three systems, they all are required to carry reserves that equal roughly $5 \%$ of annual peak demand.

The ECAR utility not only had larger outages, it also had much longer recovery times. For example, ERCOT averaged 8 outages per year for which the recovery time exceeded the

*Outage rates may be higher on weekdays because older, less reliable units are typically shut down over weekends, when capacity requirements are lower. 


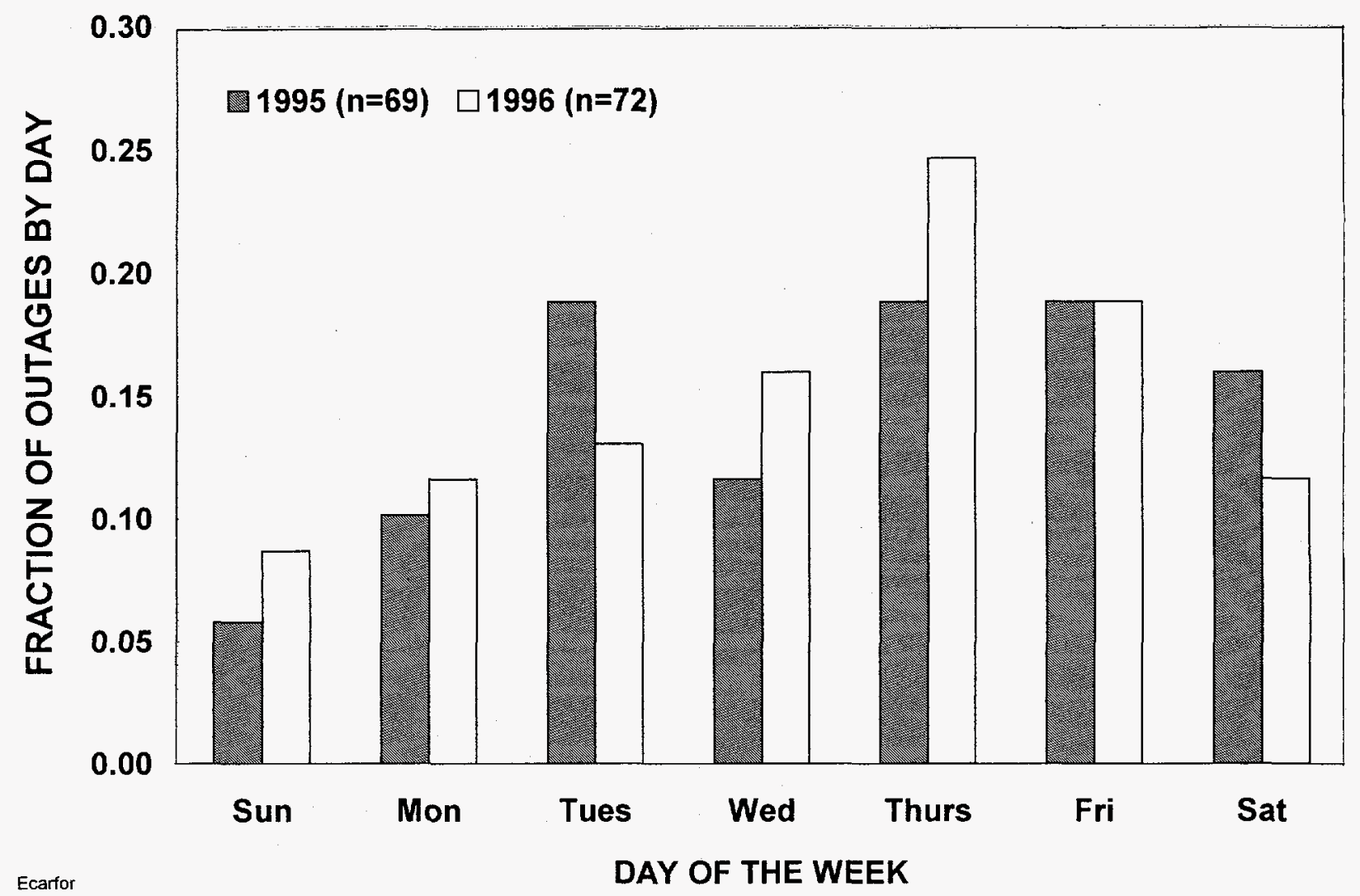

Figure 7. Frequency of generator outages by day of the week for 1995 and 1996 for an ECAR utility.

10-minute standard, NYPP averaged less than one such outage, while the ECAR utility averaged 32 such outages.

Although one might think that the recovery time would depend, among other factors, on the size of the outage, these data do not support such a hypothesis. For the ECAR utility, the correlation coefficient between outage size relative to operating-reserve requirement and recovery time was only 0.26 , for NYPP the correlation coefficient was 0.0 , and for ERCOT the correlation coefficient was -0.37 . (The negative correlation for ERCOT may occur because outages associated with larger units produce frequency declines sufficient to trigger underfrequency load shedding, which helps to restore the system to equilibrium more quickly.) 


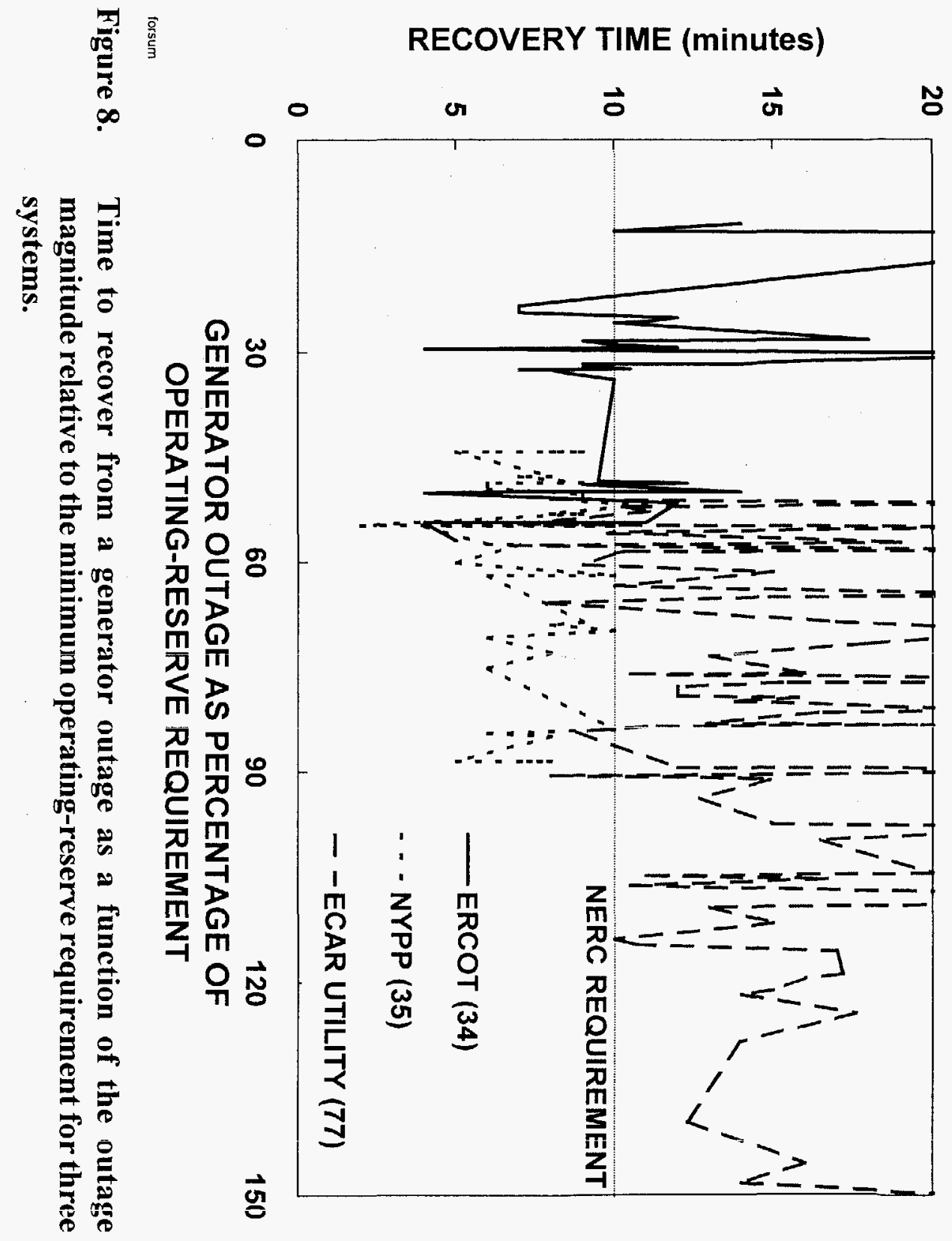




\section{DISCUSSION}

\section{TECHNICAL BASIS FOR OPERATING-RESERVE REQUIREMENTS}

NERC and the regional reliability councils are in the midst of a major transformation from a system of voluntary compliance to one of mandatory compliance with reliability requirements. The new Disturbance Control Standard is an important step in the direction of developing and implementing measurable reliability-related performance standards.

The minimum operating-reserve requirements vary from region to region. Such differences are reasonable given the variations in electrical characteristics among regions. Such differences include the density and location of loads and generators, the number and type of large generating units, transmission constraints, and the size of the interconnection (especially important for ERCOT).

Unfortunately, there appears to be only a limited published analytical basis for either the 10-minute recovery-period requirement or for the minimum-operating-reserve requirements specified by the ten reliability councils. Although we talked with many people at NERC, the councils, power pools, and individual utilities, we uncovered only two sets of studies. And these studies were 10 to 40 years old. In other words, the technical bases for these minimum operating-reserve requirements were difficult to obtain or perhaps minimal. We believe, although we cannot prove, that these requirements are based primarily on the experience and judgment of control-area operators and electrical engineers rather than on data and analysis. For example, we found no basis for the requirement that control areas calculate the disturbance control standard only for those outages that fall between 80 and $100 \%$ of the most severe single contingency. Our limited analysis of data from three control areas shows that the recovery times for smaller outages sometimes exceeds that for larger outages (Fig. 8).

Although such rules of thumb were sufficient in the past, they may not be enough in the future. In the future, customers will be required to pay explicitly for these operating reserves (because their costs will no longer be buried within the bundled electric rate they formerly paid). Customers, especially large industrial customers, and power marketers will want clear evidence that they are getting services commensurate with what they are paying for those operating-reserve services. And generators that impose less of an operating-reserve burden on the system will want to be compensated accordingly.

Operating-reserve requirements could be based on either probabilistic or deterministic calculations. In an ideal world, the reliability councils would conduct both types of analyses, 
testing the results against different sensitivities related to unit-specific forced-outage rates, capacity costs, and other factors. In general, these requirements are currently based primarilly on the magnitude of the largest single contingency. The thinking behind this approach is that the system must be able to withstand such a contingency regardless of the probability of its occurrence. In other words, even if the largest generator has an excellent reliability record (e.g., less than one forced outage a year), the consequences of such an outage are so severe, that the system must be protected against its occurrence. For example, the ERCOT requirement of 2300 MW of responsive reserve is based on the desire to avoid the loss of any firm load if any one of the region's four large nuclear units trips offline.

Table 2 presents one approach to assigning responsibility to individual generators based on the size of each unit. In this example, the system consists of 57 units with a total generating capacity of $23,500 \mathrm{MW}$. The largest single contingency is $1000 \mathrm{MW}$, equivalent to $4.3 \%$ of capacity. The incremental unit responsibility is based on the number of units of that size or larger and the difference in size between the particular generator and the next smallest size (e.g., for the $700-\mathrm{MW}$ units this incremental responsibility is equal to $200 \mathrm{MW}$ divided by 7 units). The total unit responsibility is equal to the total unit responsibility for smaller units plus the incremental responsibility for units of that size (e.g., for the 700-MW units it is equal to 12.9 MW plus 28.6 MW). This approach places what we believe is the appropriate responsibility on the larger units, especially the largest units that set the operating-reserve requirement. In this example, the 1000-MW units must provide operating reserves equal to $19 \%$ of their capacity, compared with only $2 \%$ of capacity for the $400-\mathrm{MW}$ and $50-\mathrm{MW}$ units."

An alternative approach, which we think merits additional consideration, would focus on the statistics of outages, their severity, and their consequences. In such a probabilistic approach, the performance of individual generators would figure prominently in the determination of the minimum amount of operating reserves required.

Ultimately, the "reliability" and "commercial" communities will need to agree on the appropriate tradeoffs between technical rigor and simplicity of application. While today's rules of thumb may lack technical support, they are simple to understand and apply. These rules have worked in the past, have been shown to be adequate, but may provide more reserves than are actually needed. Careful analysis of outage data may show that the optimal amounts of operating reserves are complicated functions of the mix of generators online, including unit reliability, ramp rate, and size; system load; day of the week; and perhaps other factors. We do not know whether the costs associated with the use of complicated algorithms to determine and allocate operating reserves will be justified by the economic-efficiency gains.

*An extreme system would impose all the incremental requirements on the largest unit. If the largest units in the control area were $600-\mathrm{MW}$ in size, the reserve requirement would be $600 \mathrm{MW}$. Adding one 1000MW unit would increase the reserve requirement by $400 \mathrm{MW}$. Should this large unit be responsible for the entire $400-\mathrm{MW}$ increment (equivalent to a $40 \%$ operating-reserve requirement)? 
Table 2. Example of a deterministic approach to assigning operating-reserve responsibilities to individual generators based solely on their size

\begin{tabular}{rccccc}
\hline \multirow{2}{*}{$\begin{array}{l}\text { Unit size } \\
(\mathrm{MW})\end{array}$} & $\begin{array}{c}\text { Number of } \\
\text { units }\end{array}$ & $\begin{array}{c}\text { Class } \\
\text { responsibility } \\
(\mathrm{MW})\end{array}$ & \multicolumn{3}{c}{ Unit responsibility } \\
\cline { 4 - 6 } & & 300 & $\begin{array}{c}\text { Incremental } \\
(\mathrm{MW})\end{array}$ & $\begin{array}{c}\text { Total } \\
(\mathrm{MW})\end{array}$ & $\begin{array}{c}\text { As percentage } \\
\text { of unit size }\end{array}$ \\
\hline 1000 & 2 & 200 & 28.6 & 41.4 & 6 \\
700 & 5 & 100 & 4.5 & 12.9 & 3 \\
500 & 15 & 350 & 7.4 & 8.3 & 2 \\
400 & 25 & 50 & 0.9 & 0.9 & 2 \\
50 & 10 & & & & \\
\hline
\end{tabular}

\section{PAYING FOR OPERATING RESERVES}

The current systems for assigning operating reserves do not distinguish among the performance of individual generators. In the future, we believe that the system may change in two ways.

- The operating-reserve requirements may increasingly be based on probabilistic instead of (or in addition to) today's deterministic methods. In several regions, the reserve requirement is based on the capacity of the largest unit online. This requirement, however, is completely independent of the reliability of that unit. In other words, the amount of reserves required is the same for a unit with a $1 \%$ forced-outage rate as it is for a unit with a $20 \%$ forced-outage rate. Perhaps, the amount of reserves required at any given time should depend on which generators are scheduled to be online. If that mix of generators is highly reliable, the operating-reserve requirements will be modest. On the other hand, if some of those generators have high forced-outage rates, the overall operating-reserve requirement will be higher.

- Although customers will continue to pay for operating reserves, in the first instance suppliers may pay. Specifically, each supplier could be assigned an amount of operating reserves to provide or obtain as a function of its individual unit performance. And when a particular unit trips offline, that unit could be responsible for any energy payments to generators that provided energy during the 30 - or 60 -minute period that such reserves operate.

In a competitive market, generating units that are highly reliable (e.g., those on the left side of Fig. 3) would be required to provide or pay for much less operating reserves than would the units that experience frequent outages. This economic signal would provide the appropriate incentive to generation owners, encouraging them to undertake the amount of maintenance that would just balance the higher cost of providing more operating reserves. In addition, when an outage occurs and operating reserves are called upon, the generator responsible for the outage 
would pay the operating costs of the units that responded to the outage (i.e., the incremental fuel plus operating costs beyond those associated with the spot-market price for that hour). This pricing approach would eliminate subsidies among generators and would provide further incentives to generator owners to maintain high availability levels at their units.

\section{FUTURE DATA NEEDS}

We found it surprisingly difficult to obtain even the most basic data on forced outages. Utilities, power pools, and regional reliability councils are often unable to readily provide information on the frequency and consequences of outages. Accurate and complete data are especially difficult to obtain. We were unable to obtain data from any control center on related factors, such as the number of units online at the time of the outage, the amount of operating reserves online, and whether the unit that tripped offline was also providing operating reserves.

The limited analysis presented here shows that the time to recover from an outage is largely independent of the size of the outage. This conclusion implies that other factors (perhaps including those listed above for which we were not able to obtain data) are influential in determining how quickly the system recovers from an outage. Electric-system operators need to collect, verify, report, and analyze such data for two reasons:

- to ensure that the minimum-operating reserve requirements are supportable (i.e., they appropriately trade off costs and benefits); and

- to understand the performance of control areas and individual generators in maintaining reliability.

Because a competitive electricity market will likely insist on technically defensible reserve requirements, we recommend that NERC collect more data along the following lines: unit output (MW) immediately before the outage, unit capacity (MW), system load at the time of the outage (MW), system operating reserves at the time of the outage (MW), number of units online at the time of the outage, and the time to return $\mathrm{ACE}$ and frequency to their precontingency values.

\section{MIXING FUNCTIONS WITHIN OPERATING RESERVES}

Currently, operating reserves are often used to protect against load-forecast errors as well as supply outages. Here, too, what worked well in the past may not work in the future. We worry about the advisability of assigning operating reserves to two disparate functions. The load-forecast errors and generator forced outages represent very different phenomena, with the former being a commercial function and the latter a bulk-power reliability function. The cost of maintaining reserves to protect against generator outages should, as discussed above, fall on those generators responsible for the operating-reserve requirement (e.g., with frequent forced outages or large unit sizes). The cost of maintaining reserves to protect against load-forecast 
errors should be assigned to those customers or scheduling coordinators that forecast poorly; these costs should appear in the load-following or energy-imbalance service, not in operating reserves. The California proposal includes a charge "to allocate costs associated with the dispatch of replacement reserves to those scheduling coordinators who contributed to the imbalance energy [what others call energy imbalance] requiring such dispatch" (Pacific Gas and Electric et al. 1997).

Operating reserves often include regulation (the use of generating units to follow minute-to-minute fluctuations in system load), which we think should be treated separately. Generators that provide regulation grant the system operator the right to vary the outputs of their units up or down, from minute to minute, within a specified range ( $\pm x$ MW with a ramp rate of $y \mathrm{MW} /$ minute). Generators that provide operating reserves grant the system operator the right to increase (but not decrease) the output from their units when a major disturbance occurs. Based on the data analyzed here, a unit providing operating reserves can expect to be called upon to provide those reserves once or twice a month. Thus, the operation of generators for regulation differs substantially from the operation of those units for operating reserves. Combining these two disparate functions is inappropriate. 



\section{CONCLUSIONS}

Historically, the North American electric systems have been the envy of the world. These systems provide electricity to consumers with a remarkably high level of reliability. However, the structure and operation of bulk-power systems are changing rapidly because of the introduction of competition into what has historically been a heavily regulated industry. As Stalon (1997) noted, developing reasonable governance structures for this new industry that appropriately balance commerce and reliability will be difficult.

Thus, the establishment of reliability standards, such as those associated with minimum operating-reserve requirements, can no longer rely so heavily on rules of thumb and the experience and judgment of system operators. In the future, with more and more participants in bulk-power markets, many of which will be motivated primarily by profits, pressure will grow to answer key questions about these requirements. What is the basis for deciding how much operating reserves are required? How do these requirements vary from hour to hour, day to day, or season to season? What are the tradeoffs between cost and reliability of having more or fewer operating reserves? Who (perhaps including customers) is eligible to provide these services? And who should pay for these services?

Bulk-power market participants might reasonably ask how much money could be saved by extending the maximum allowable recovery time from 10 to 15 minutes (which, presumably, would reduce the amounts of spinning and supplemental reserves required and their minimum ramp rates). How much more vulnerable would systems be to a second outage that might occur before the system was restored to balance? By how much would reliability be improved if the recovery time were shortened from 10 to 8 minutes?

In response to these new and growing challenges, NERC, the regional reliability councils, independent system operators, and control-area operators will need to do a better job of collecting, reporting, and analyzing data on outages. They will need to use these data to provide firm support for minimum-operating-reserve requirements. They will need to split commercial functions from the reliability functions of operating reserves; that is, load-forecast error should be incorporated into either the energy-imbalance or load-following ancillary service. Finally, system operators should rely on competitive markets to the maximum extent practical to procure and price operating reserves (Hirst 1997; Hirst and Kirby 1997). 


\section{ACKNOWLEDGMENTS}

We thank Timothy Bush, Michael Curley, Dennis Hogan, Robert Kelley, Michael Potishnak, and David Sutherland for supplying us with data on generator forced outages and system-recovery times. We thank Romulo Barreno, Donald Benjamin, Nick Brown, Paul Carrier, Gerry Cauley, Stephen DeMarco, Joseph Hipius, John Hughes, Kim Khu, Erle Nye, Michael Potishnak, Ted Reece, Antonio Sammut, Charles Stalon, David Sutherland, Susan Tierney, and Robert Trapp for their very helpful comments on a draft of this report. We thank Fred O'Hara for editing the report, and we thank Ethel Schorn for managing the clearance, publication, and distribution processes. 


\section{REFERENCES}

G. A. Cucchi, D. J. Pratzon, and F. P. Witmer 1976, "Experience with Generation Outage Data Collection Procedures on a Large-Scale System," IEEE Transactions on Power Apparatus and Systems PAS-95(2), 542-549, March/April.

M. Curley 1997, personal communication, North American Electric Reliability Council Princeton, NJ, September.

Electric Reliability Council of Texas 1987, Working Papers for the Group I Studies of the 1987 Spinning Reserve Task Force, Austin, TX, July.

Electric Reliability Council of Texas 1997, ERCOT Operating Guides, Austin, TX, July.

E. Hirst 1997, Competition Can Enhance Bulk-Power Reliability, Electricity Consumers Resource Council, Washington, DC, June.

E. Hirst and B. Kirby 1996, Electric-Power Ancillary Services, ORNL/CON-426, Oak Ridge National Laboratory, Oak Ridge, TN, February.

E. Hirst and B. Kirby 1997, Creating Competitive Markets for Ancillary Services, ORNL/CON448, Oak Ridge National Laboratory, Oak Ridge, TN, October.

Interconnected Operations Services Working Group 1997, Defining Interconnected Operations Services Under Open Access, EPRI TR-108097, Electric Power Research Institute, Palo Alto, CA, May.

Mid-America Interconnected Network 1995, Main Guide No. 5A, Operating Reserve, Lombard, IL, May 12.

New England Power Pool 1996, New England Power Pool (NEPOOL) Restructured Arrangements (including Open Access Transmission Tariff), before the Federal Energy Regulatory Commission, Holyoke, MA, December 31.

North American Electric Reliability Council 1995, NERC Operating Manual, Princeton, NJ.

North American Electric Reliability Council 1996, Performance Standard Training Document, Princeton, NJ, November 1. 
Pacific Gas and Electric, San Diego Gas \& Electric, and Southern California Edison 1997, The Phase II Filing of the California Independent System Operator Corporation and The Phase II Filing of the California Power Exchange Corporation, Docket Nos. EC96-19-001 and ER961663-001, before the Federal Energy Regulatory Commission, San Francisco, San Diego, and Rosemead, CA, March 31. See also revised August 15, 1997 filing.

C. G. Stalon 1997, "Electric Industry Governance: Reconciling Competitive Power Markets and the Physics of Complex Transmission Interconnections," Resource and Energy Economics 19(1-2), 47-83, March.

U.S. Federal Energy Regulatory Commission 1996, Promoting Wholesale Competition Through Open Access Non-Discriminatory Transmission Services by Public Utilities; Recovery of Stranded Costs by Public Utilities and Transmitting Utilities, Final Rule, Docket Nos. RM95-8000 and RM94-7-001, Order No. 888, Washington, DC, April 24.

U.S. Federal Energy Regulatory Commission 1997, Promoting Wholesale Competition Through Open Access Non-discriminatory Transmission Services by Public Utilities; Recovery of Stranded Costs by Public Utilities and Transmitting Utilities, Order on Rehearing, Docket Nos. RM95-8-001 and RM94-7-002, Order No. 888-A, Washington, DC, March 4.

S. Virmani, E. Lo, and D. McNair 1992, Impacts of Governor Response Changes on the Security of North American Interconnections, TR-101080, Electric Power Research Institute, Palo Alto, CA, October.

Western Systems Coordinating Council 1997, WSCC Operating Reserve White Paper, Salt Lake City, UT, June 4.

C. Wright 1997, personal communication, North American Electric Reliability Council Princeton, NJ, September. 


\section{INTERNAL DISTRIBUTION}

1. L. Baxter

2. V. D. Baxter

3. L. Berry

4. D. J. Bjornstad

5. M. A. Brown

6. J. Christian

7. G. Courville

8. T. R. Curlee

9. P. D. Fairchild

10. S. Hadley

11. L. J. Hill

12. E. Hirst

13. P. J. Hughes

14. B. Kirby

15. R. Lee
16. P. Leiby

17. J. M. MacDonald

18. V. C. Mei

19. D. E. Reichle

20. A. C. Schaffhauser

21. M. Schweitzer

22. R. B. Shelton

23. J. Tomlinson

24. B. E. Tonn

25. J. Van Dyke

26. J. VanCoevering

27. T. J. Wilbanks

28. Central Research Office

29. Document Reference Section

30. Laboratory Records (RC)

\section{EXTERNAL DISTRIBUTION}

31. Dr. Lilia A. Abron, President, PEER Consultants, P.C., 1000 N. Ashley Drive, Suite 312, Tampa, FL 33602

32. Dr. Thomas E. Drabek, Professor, Department of Sociology, University of Denver, Denver, CO 80208-0209

33. Dr. Stephen G. Hildebrand, Director, Environmental Sciences Division, Oak Ridge National Laboratory, P.O. Box 2008, Oak Ridge, TN 37831-6037

34. Mr. P. Richard Rittelmann, FAIA, Executive Vice President, Burt Hill Kosar Rittelmann Associates, 400 Morgan Center, Butler, PA 16001-5977

35. Dr. Susan F. Tierney, The Economic Resource Group, Inc., One Mifflin Place, Cambridge, MA 02138

36. Dr. C. Michael Walton, Ernest H. Cockrell Centennial Chair in Engineering and Chairman, Department of Civil Engineering, University of Texas at Austin, Austin, TX 78712-1076

37.-38. OSTI, U.S. Department of Energy, P.O. Box 62, Oak Ridge, TN 37831

39.

Office of Assistant Manager for Energy Research and Development, DOE/ORO, P.O. Box 2001, Oak Ridge, TN 37831-8600

40.-700 External Electric Industry Policy Studies group distribution mailing list and extra copies to E. M. Schorn, 4500N, H-19A 